\title{
Empirical Study of Student Complacence for Educational Consumption in the Colleges and Universities of Jiangxi Province
}

\author{
Shi Jing \\ Nanchang Institute of Technology, Economic and trade \\ College, Nanchang, Jiangxi \\ Nanchang, China \\ e-mail:sj_engel@163.com
}

\author{
Zheng Zhi \\ Nanchang Institute of Technology, Economic and trade \\ College, Nanchang, Jiangxi \\ Nanchang, China \\ e-mail:sj_engel@163.com
}

\begin{abstract}
With the progressive intervention of market forces into the higher education filed, the students' satisfactions with educational consumption in the higher learning institutions has become one of key factors that determine the success or failure for the competition between the colleges and universities, which has aroused the high attentions of the institutions and other sectors, however, the research in this issue needs to be further substantiated Attaching importance to the issue is not only the requirement of transforming operational concepts , but also the requirements of improving the quality of higher education. The testing and appraisal of students' satisfaction with educational consumption is the effective measure and instrument that assesses the qualities of schools. At present, the satisfaction of educational consumption is not high, the analysis indicates that the influencing factors consist of teaching service quality, campus cultures and management system, and the below efforts should be made to improve the satisfaction:
\end{abstract}

Key words-Complacence of eductional consumption ;higher educaiton ; educaiton qualtiy .

\section{Forward}

As the major consumers of education, university students' complacencies have a direct bearing on their assessments of the education quality. In order to have knowledge of the status of students' satisfaction in the colleges and universities of Jiangxi Province, this study employs the five institutions of Jiangxi Province as the investigation objects to carry out the empirical study. The empirical study was executed to the objects so that the validity of questionnaires can be ensured. In order to guarantee the validity, the total 30 postgraduates of master and doctor as well as teachers of each major have been invited successively to have informal discussions of the reasonableness of questionnaire's compilation and they made the assessment that whether the questionnaires can actually reflect the reality and proposed the precious suggestions. After that, the repeating revises of the questionnaires, conducted in accordance with the suggestions, enable the questionnaire to boast certain representativeness and operability. The contents of the questionnaire, from the perspectives of students, aim at knowing the students' attitudes towards learning, their satisfactions with school (including teaching and administrative staff, teaching management system, facilities and environment), their satisfactions of the level of acquiring the knowledge, their opinions in the education level as well as the suggestion of improving the teaching quality and so on. This investigation, employed the stratified random sampling, has totally given out 500 questionnaires, and 480 were retrieved with 96 percent recovery, among of which there were 476 valid questionnaires, making the valid rate 95.2 percent.

\section{THE CURRENT STATUS AND RESULT ANALYSIS OF EDUCATIONAL CONSUMPTION SATISFACTION FOR THE STUDENTS IN COLLEGES AND UNIVERSITIES.}

2.1 The basic information of each index

2.1.1 The statistics of frequency for each dimension index after evaluation

(1) The images of schools: the scores distribute in the range from 2.67 to 3.67 , the dimensional factor of "School image" doesn't fluctuate sharply and presents the balanced status; the images of colleges and universities of Jiangxi Province are relatively good among the students.

(2) Teaching service: The scores are low as a whole, mainly students in the colleges and universities are not satisfied with the teaching service as a whole. The schools should attach importance to it and strengthen the reform of teaching service to improve the teaching quality and enhance students' complacence of the service.

(3) Service of the libraries: The scores are relatively high as a whole, mainly gathering between 2.50 and 4.25, and among of which the scores around 2.50 rank the first place. The factor of "library services" boasts the relatively high score as a whole, which indicates that students in the colleges and universities are relatively satisfied with the service.

(4) Student management and supporting service: their scores are situated between 2.17 and 3.67, the scores are relatively low as a whole, and among of which the scores around 3.00 account for the most part. It indicates that the colleges and universities of Jiangxi Province should take students as the principal part to improve their services that were conducted to the students with the hope of enhancing students' satisfactions.

(5) The atmosphere of campus cultures: the scores mainly fluctuate between 2.40 and 3.80 , the scores are relatively low as a whole, and among of which the scores around 3.00 take the lead. It indicates that the colleges and universities of Jiangxi Province should pay attention to the construction of campus culture and 
emphasize the cultural accretion to form campus cultures with their own unique characteristics

(6) Logistics service: the scores mainly are present between 2.00 and 3.57 , they are relatively low as a whole, and among of which the scores around 3.00 is the primary part. It indicates that the colleges and universities of Jiangxi Province should strengthen the rectifying of logistics to better solve the issues of students' daily lives and create the better living conditions for students. Meanwhile, we should promote the quality and level of logistics service to increase the students' satisfactions.

\subsubsection{The frequency statistics of overall satisfactions}

The satisfaction of each investigation object with the students' educational consumption scores rarely below 2.50 or more than 3.50 , mainly distributing between 2.50 and 3.50, and the average score of the overall students' satisfactions with educational consumption in the colleges and universities of Jiangxi Province are relatively low , and which matches the expectations of authors.

2.2 The analysis of individual features' impact on satisfaction

\section{The impact of student source on the each dimension and the whole satisfaction.}

The investigations show that the four dimensional factors of the entire complacence, student management with supporting service, campus culture and logistics service vary as per the changes of the domiciles of student sources. The student management with supporting service and the atmosphere of campus culture are impacted by the domiciles of student resources substantially and enjoy the following trends: the rural students have higher satisfaction with the overall satisfaction than students in the cities and towns, student management with supporting service, atmosphere of campus culture and logistics service ; while the influence of domiciles of student resources on the factors like school image, teaching service, library service and students' perception values, are not outstanding .

\section{The impact of grade on each dimension and the whole satisfaction.}

The grade has a marked impact on the two dimensional factors of the atmosphere of campus culture and logistics service while there is no prominent difference of the impacts on other dimensional factors

\section{The influence of gender on each dimension and the whole satisfaction.}

Gender has the impact of conspicuousness only on the one factor of teaching service , and girl students' satisfaction are slightly higher than that of boy students, and there is no prominent difference of the impacts on other dimensional factors.

\section{The impact of branches of learning on each dimension and the whole satisfaction.}

The students' satisfaction appraisals of three dimensional factors of teaching service, student management with supporting service and student perception value vary according to the different disciplines, among the three, student perception value is impacted by branches of learning significantly while there is no prominent difference of the impacts on other dimensional factors.

5. The impact of faculty on each dimension and the whole satisfaction.

The students' satisfaction with the six dimensional factors of students, such as the whole satisfaction, teaching service, student management with supporting service, atmosphere of campus culture, logistics service and student perception value, all vary according to the change of faculty, especially the whole satisfaction, teaching service, student management with supporting service and the service of student perception value are affected by the faculty notably; and the school image is the only one that impacted by factor of faculty slightly.

\section{THE INFLUENCING FACTORS OF THE WHOLE SATISFACTION}

In order to study the extent of influence on the whole satisfaction caused by individual features, the product moment correlation analysis of investigation data was conducted, and the results are shown in the below tables .

Table1. The correlation analysis of the whole satisfaction and school image.

\begin{tabular}{llll}
\multirow{2}{*}{ Item } & & & \\
& & & \\
\hline \multirow{2}{*}{ The whole satisfaction } & Person correlation & 1 & $0.419\left(^{*}\right)$ \\
& Conspicuousness (bilateral) & - & 0.000 \\
School image & Person correlation & $0.419(* *)$ & 1 \\
\hline
\end{tabular}

** There is significant conspicuousness at the level of .01.

Table2. The correlation analysis of the whole satisfaction and teaching service

\begin{tabular}{llll}
\hline \multirow{2}{*}{ Item } & & & \\
& & & \\
& & & \\
\hline \multirow{2}{*}{ The whole satisfaction } & Person correlation & 1 & $0.669\left(^{*}\right)$ \\
& Conspicuousness (bilateral) & - & 0.000 \\
\multirow{2}{*}{ Teaching service } & Person correlation & $0.669(* *)$ & 1 \\
\hline & Conspicuousness (bilateral) & 0.000 & - \\
\hline
\end{tabular}

** There is significant conspicuousness at the level of .01.

It can be perceived from the table 1 that the whole satisfaction and school image enjoy the marked positive correlation and the amount of variability for the whole satisfaction that can be explained by the school image accounts for 17.56 percent. While from table 2, we can see that there is significant positive correlation between the whole satisfaction and teaching service, and the percent of amount of variation that can be explained by teaching service in the amount of variation for the whole satisfaction is 44.76 . What we can judge from the analysis( the table was omitted) in the same method as above is that the outstanding positive correlation exists between the whole satisfaction and library serve, between student management and supporting service , logistics service and student perception value, and in the amount of variation of the whole satisfaction , the percent of the amount of variation that can be explained by library 
service is 39.56, that of the atmosphere of campus culture is 52.85 , that of logistics service is 56.10 and that of student perception value is 48.31 .

The SPSS method, the same as above, was employed to analyze the extend of influence on the whole satisfaction caused by the factors like the atmosphere of campus culture, student perception value ,teaching service ,library service, student management with supporting service and logistics service and so on . As per the above analysis, the sequencing of the influencing factors according to the importance for the students' satisfaction with the educational consumption in the colleges and universities of Jiangxi Province is as below: student management with supporting service, logistics service, atmosphere of campus culture , perception value of student, teaching service, library service and school image. It also indicates that student management with supporting work is the most unsatisfactory items for students in the colleges and universities of Jiangxi Province while the logistics service and atmosphere of campus culture is secondary, and students are relatively satisfied with the library service. Meanwhile, the impact of teaching service on the whole satisfaction is not that vital as what was expected, but teaching is still the key point and core for the overall educational service consumption, which reflects that students' feelings about the teaching services offered by the schools are no great difference. With the intervention of marketization factors, the traditional relationships between teachers and students have been changed qualitatively, and the students are on longer the educated men while the teachers do not merely play the role of "delivering a sermon, teaching and handling queries". With the new educational concept that advocates "centering on the student consumers", we are in more need of constantly strengthening the teaching work to improve the teaching service level, catering to the all-round needs of students on the premise of meeting the students' basic demands. Schools should transfer the traditional teaching that only pays attention to the educational quality to focus on the students' feelings, and attach more importance to the students' lives, taking the student management and supporting service seriously. in addition, among the various influencing factors, the logistics service accounts for the relatively big proportion ,therefore, changing the concept of logistics service to improve the level of service is quite vital .As the library undertakes the important task of being the first battle field, the library service should be consolidated continually ,expand the areas of service and improve the service quality ,meanwhile , the fund investment should be increased to expedite the constructions of libraries so that more and better ideological sustenance can be offered to the students.Meanwhile, the higher learning institutions should spent more time and energy on the construction of campus culture, forming the campus cultures with unique characteristics that will be accepted by the student; pay more attention to care about the sound bodies and minds of students and lay stress on the students' capacities for practices and social activities; strengthen the interpersonal interaction to create a friendly , energetic , sound and harmonious environment so as to promote the students development in body and mind and improve their capacities. The managers of student management should merge their loves in the each step of the above work, and they should don't only care about the students' learning, but also care about the students' daily lives, working with more initiatives and more passions to make the students feel the warmth of schools and teachers' mildness.

The each aspect of students' lives in the school is likely to affect the student's appraisals of satisfaction with educational service consumption, and the soft environment boasts the bigger impact on the satisfaction of student consumers than that of hard environment, which is a transformation of working statuses of the higher learning institutions in the new period. The institutions should realize the change, update the concepts of running a school and introduce the strategy of "the satisfaction of student consumers", which should be firmly implemented in the actual works, and the students' interests should be put at the first place when taking any action, meanwhile, each work needs to be centered on the students, and the students' feelings should be known and paid attention. For the works and services that students are satisfied with, we should continue to keep them, and for the points that have not satisfied the students, the effective measures should be taken to achieve the timely improvement.

IV. THE REASONS FOR THE LOW SATISFACTION OF THE STUDENTS IN THE COLLEGES AND UNIVERSITIES IN JIANGXI PROVINCE.

According to our investigation, we found the satisfactions of the university students are very low, which is consistent with the hypothesis made by us previously. The roots consist of the below points:

First, the managements of the higher learning institutions have not changed the concepts thoroughly, and have not worked on the basis of students without fully taking the university students as the "consumers" that receive the educational services. for this very reason that the transformation ,from taking students as the men that merely receive education to the consumers that spend money on the educational services, failed to be achieved, and the managers at all levels work with colleges and universities often pose as the "governors" ,meanwhile , the traditional concept of "the absolute authority of the teachers" is ingrained, which is impossible to be abandoned in short time while teachers' attitudes towards students can not be very modest and their working mode also lack the hommization. With increasingly fierce completions in the market of higher education, the higher learning institutions have realized the importance of students for the schools' survival and development, and increasing number of institutors are shouting the slogan of "everything centers on the students", but which always enjoy the gap with reality.

Second, the market of higher education in China is mainly taken by the seller's market, and the institutions have not fully been aware that the importance of self adjustment and self-improvement in the conditions of 
market operation, so they has shown the low sensitivity to the issues of educational consumption satisfaction that the university students care about, and this impacts and determines that the lacking of attentions to the students' interests and demands in various appraisals.

Third, the managements of the institutions have not treat the student' complaints seriously in the routines, nor taken the relevant remedies, therefore, the vicious cycle of students perception has been taken shape. When the breath of marketizaiton come from straight ahead, the students have naturally realized the meaning of paying tuition and they on longer treat themselves as the mere men that receive education, requesting their proper rights to be protected and asking for importance to be attached to their feelings . At this moment, if the students' expectation of the institutions were returned with repeated illusions, the students' disappointment to the institutions would become deeper. Students are the consumers of the services offered by the institutions, so the school should not treat their complaints or comments roughly. Elevated people should realize that no matter how trifling the point is, it is likely to be the key points that probably lead to the dissatisfaction with the whole educational service. If in this situation, the managements of the institutions have not attached importance to the investigation result of consumers' satisfactions, and only regarded as a formality, nor seriously study and discuss the dissatisfactions and the reasons, nor take the timely relevant remedies, the strong antipathies of students will be aroused inevitably, thereby, resulting in the vicious cycle and the students' satisfactions with the institutions will be increasingly lowered.

In summary, we can see that: the low student satisfaction is already a fact, the roots for this situation are mainly suited at the rigid concepts of providers of educational service, who have not fully treated the "satisfaction of student consumer" as an operational idea and get the idea implemented in the each point of routines for colleges and universities.

\section{THE COUNTERMEASURES OF IMPROVING THE UNIVERSITY STUDENTS’ SATISFACTION WITH EDUCATIONAL CONSUMPTION}

Because of the actual status of the students' satisfaction with educational consumption, the higher learning institutions should try everyway to enhance the complacence of educational consumers. Therefore, we should probe the below points and put them into practice:

\subsection{Improving the satisfaction of teaching service}

First, we need to pay attention to foster the students' conscious activities and strengthen the virtuous cycle of the interactions between teachers and students in the process of teaching, attach great importance to individual differences and personal features, and increase students' interest in their majors by means of interesting teaching, carrying out a variety of academic exchanges and so on. Second, we should take the students' demands as the guidance to optimize and configure teaching resources of schools and constantly boost the mode reform of talent training. Third, we should strengthen the construction of teachers' moralities and morale, encourage teachers to continually improve their comprehensive competences, guide teachers to pay attention to the physiological health and mental health, and which will be employed to affect and bring along the students to be the persons of all-round development. Forth, we should establish the sound mechanism of teachers' selection and appraisal to choose the talents of echelon with high academic attainments and capacities for leading and organizing their own disciplines, meanwhile, we should stringently formulate and implement the appraisal system of teacher's duty performances .

\subsection{Strengthening the construction of campus culture}

The institutions should constantly improve the grade and level of the construction for higher learning institutions. They should provide the favorable campus environments; meanwhile, they should pay attention to form the excellent campus culture that "students are satisfied with", which aim at approaching the schools' historical traditions ,structure and target training, carry out the activities of campus culture with rich contents, novel forms and strong attractiveness , among of which university students' ideologies and emotions can be nurtured, their intellectual lives get enriched and their moral level get improved, and in this way , boosting the formation of "university spirit" with the characteristics of higher learning institutions , and supporting the continuous developments and progresses of the institutions by means of the spirit.

\subsection{Improving the service level through strengthening} logistics administration.

First, setting up the service concept of "students' satisfaction", the managers of higher learning institutions that aim at realizing the satisfaction of the logistics service concepts should normalize and standardize the management systems of schools, enable all faculties to really understand the importance of the strategy of satisfaction of student consumers through ideological and knowledge education with conduct training, meanwhile, we should make more efforts to training of service standards, service attitudes ,professional knowledge and service skills for logistics service personnel. In order to achieve the actual students' satisfactions, we should take the concept of "satisfaction of student" as the guidance for everything, and the concept should be implemented conscientiously.

Second, having knowledge of students' pursuits and providing more excellent services. The educational consumption of students in colleges and universities runs through the whole process of students' schooling, so the managements of the institutions should pay more attention to care about the students' lives besides providing superior teaching services, while the logistics is the important guarantee for students' learning and lives, therefore, the perfect conduct satisfaction system should be established to achieve the satisfaction with the conducts of logistics 
services. First, the logistics of the institutions should formulate one set of mechanism for excitation, restraining, development and supervision, which are scientific with relatively strong operability and management so as to ensure the normal operations of various service systems for logistics. Secondly, they should meticulously arrange the service procedure and accomplish the standardized curb of the conducts for enterprises and faculty according to law through formulating and perfecting the standardized rules and regulations of enterprises. Third, they should set one whole set of conduct model, for example, carrying out the examination and appraisal for star personnel each season and strengthening rewards and punishments, holding a symposium or paying a return visit each half year and attaching importance to the students' complaints with executing the activities like the forum of interior staff and so on per half year to keep the comments feedback system of logistics unimpeded. In addition, we should actively create conditions to provide students with better supporting living conditions

\subsection{Establishing the scientific and reasonable excitation mechanism for students}

We should establish the scientific and reasonable excitation mechanism for students and combine excitation of matter and mind, especially the ideal excitation. As the university students just stepped in their youths with immature mentality, particularly the shallow experiences, feelings and cognitions, they are prone to have varied confusions and befuddlement, so the measures of excitation should be employed to guide them to generate spiritual impetuses for the goal that they strive for so that their initiatives of learning can be strengthened to enable them to better pursue their own dreams

\subsection{Attaching importance to the construction of school image}

The impact of school image on the student consumers, including the potential consumers, should be never neglected, a great part of influence is from public opinions and Medias as well as the consumers' praises. The institutions should make a point of the details and improve the satisfactions of consumers, and then enhance their loyalties, making more consumers know and understand the school images through the dissemination of consumers' praises. Meanwhile, the institutions should take the formulation of brand image as the target in the process of their educational marketing to configure the school resources more reasonably and better integrate schools' values, and more effectively achieve the values of functionality for schools' brands so that the institutions pay more attentions to the quality management of "all-round, the whole process, all staff”. The institutions should make consumers identify the specified signs through the operation of schools' brands to improve the approbations, trusts and purchasing desires of consumers for the schools' educational products. the personnel serve in the institutions all should establish the awareness of brand strategy, formulate the practical and feasible tactics with consistency on the basis of strategy , taking comprehensive supporting measures to build the brand images of schools ,expanding the brand effects and promoting the appreciation of the brands.

\section{REFERENCES}

[1] Chen Jianda. How to improve the satisfaction of student[J].Art of Education.2001,(11): 15-16

[2] Fu Zhenfang. Empirical analysis and study for the students in the higher learning institutions [J].Forum of higher education. 2004.(5):15-16.

[3] Ji Xiaoyi. Huang Xiaoping. The study of testing and appraisal for the educational service quality of higher education $[\mathrm{J}]$. The development and assessment of higher education. 2005, (1):35.

[4]Lee Dequan. On the testing and appraisal mechanism of satisfaction with topic of "taking the consumers as the focus" for the higher learning institutions [J]. The journal of Western ChongQing University (social science version).2005, (3):16.

[5]Liu Junxue, Lee Zhenghui.The influencing factors for the university students' satisfactions with their schooling and the empirical study of their extents [J].the study of higher education. 2006, (11):92.

[6]Liu Junxue.Wang Xiaobing. On the "service concept of higher education” [J]. Study of China higher education, 2004, (3):23- 24.

[7] Liu Junxue. Updating concepts and improve the students' satisfactions with their schooling[J].China higher education , 2004, (7):36-37

[8]Liu Ziyuan. Theoretical analysis and empirical study of the influencing factors in customers' satisfactions [D]. Hunan University. 2004:11.

[9]Tao Meizhong. On the essence of educational consumption [J].Education and economy. 2007, (4):19-20.

[10] Fan Xianzuo. New economics of education [M].Nanchang: Education press of Jiangxi Province .1995:10. 